The chapter on petroleum includes a list of hydrocarbons (ranging up to $\mathrm{C}_{32} \mathrm{H}_{66}$ ), sulphur, nitrogen and oxygen compounds, which have been identified in crude oils, a total of about 450 compounds. This useful compilation gives the amounts, where known, the crude oil, and references to the sources of the information. The chapter on the origin and elassification of naturally occurring carbonaceous substances includes charts classifying coals, kerogen rocks and coals, and solid fuels of known vegetable origin. As a key to further information the book is especially valuable, and another excellent feature is its extremely full index (with, however, a few unexpected omissions); indeed, references and the index take up some 19 per cent of the space.

There can be few geologists dealing with sedimentary rocks who will not find something in this book which will be of interest; those concerned with the fossil fuels will find much of interest. Solubility, precipitation, cementa. tion, all tend to conjure up pictures of inorganic environments, where rocks are involved, yet organic matter or living organisms may play a vital part in these phenomena in numerous cases. The mechanism of the precipitation of calcium carbonate as a component of sedimentary rocks is still a subject of debate, and selectivity of some kind is indicated for the removal of silica from what are seemingly under-saturated solutions of this substance.

Detective work based on the recognition of fragments of large molecules is proving helpful in identifying the likely parent materials, while some molecules are now known not to be such definite pointers to a unique organic source as was thought to be the case. Molecules with a mission in life may well be present in sediments, but their disentanglement from the complex mixtures of organic substances, in which they probably occur as quantitatively minor components, is an operation fraught with many difficulties, not the least of which is the separation of the organic matter from the associated mineral matter, without alteration of the former. These are only a few of the fascinating achievements and possibilities in organic geochemistry, and thoughtful examination of the various chapters in Organic Geochemistry will prove stimulating to many readers, whether they be geologists, soil chemists or others. Obviously, more data are needed on the composition of living and decaying organisms, especially those which may be incorporated in sediments. The book also shows that the obtaining of anything more than superficial information on the organic matter in rocks and recent sediments is commonly a difficult and time-consuming process, in spite of the wonderful capabilities of the various kinds of chromatography.

During the past eighteen months Europe has had two symposia, and the United States at least two symposia and a Gordon Research Conference, at which some aspects of organic geochemistry have been the main topic; another symposium is planned for this year. With Organic Geochemistry. Prof. I. A. Breger and his associates have given the subject a good start in the matter of major comprehensive publications.

G. D. Hobson

\section{FLUID MECHANICS IN CHEMICAL ENGINEERING}

Fluidised Particles

By Dr. J. F. Davidson and Dr. D. Harrison. Pp. xv+ $155+11$ plates. (Cambridge: At the University Press, 1963.) 35s. net.

THE use of fluidized beds in chemical engineering and in mining as well as in other engineering processes is a well-established practice, but it is only in the past few years that they have been investigated in detail as problems in fluid mechanics. It is fortunate for chemical engineers and for workers in applied mechanics that two of the leadors in this field have written this connected account of the subject in which they and their colleagues have made the most significant advances. That solid particles can be held apart and fluidized by an upward current of fluid flowing between them is well known. That the fluidized bed so formed can be either uniform or agitated by the separation of discrete bubbles of fluid is perhaps less well known and certainly has not been understood. The key to understanding the situation lay in the recognition of an analogy between the discrete masses of fluid rising through the bed and large air bubbles rising in water.

To workers in fluid mechanics, perhaps the most interesting section of Fluidised Particles is contained in Chapters 4 and 5, where the modification of the bubble analogy needed to take account of the separate motions of fluid and particles is worked out.

Among the most striking of the theoretical predictions which were verified experimentally was that when the vertical velocity of the bubble is greater than that of the interstitial fluidizing fluid a sheath of the latter surrounding the bubble is carried up with it. The fluid in the sheath travels in closed streamlines which lie partly inside the bubble and partly outside it.

To workers in fluid mechanics the book will be valuable because it introduces a subject which is developing rapidly but is not yet completely understood. The mechanics, for example, of the process by which fluidized particles are able to offer resistance to the surrounding fluid when the flow is not vertical is not clear, in any event to me. The magnitude and direction of the interparticle forces are deduced as a result of a reasonable assumption that the reaction between fluid and particles is the same as that which supports the particles against gravity during incipient fluidization, and the motion of the particles is taken to be that which makes the whole mechanical system selfconsistent. These interparticle forces must be the result of particle impacts just as the pressure in a gas is due to molecular impacts, and the question whether there is any relationship between this impact pressure and the local rensity of particles in the bed seems to need an answer. The effective viscosity of the bed might perhaps also be treated from this point of view.

The designer of fluidized beds for industrial use will find the book valuable because it will enable him to make a reasoned choice of the elements of his design and will help him to predict its limitations. The bearing of the fluid mechanical results on the use of fluidized beds in chemical operations is discussed in Chapter 6 and three appendixes are added to assist those unfamiliar with the methods used in fluid mechanies.

The volume has a full bibliography containing about 140 references, few of which are more than five years old.

GEOFFREY TAYLOR

\section{RECENT DISCOVERIES IN PHYSICAL ORGANIC CHEMISTRY}

\section{Advances in Physical Organic Chemistry}

Vol. 1. Edited by V. Gold. Pp. xv + 443. (London: Academic Press, Ine. (London), Ltd. ; New York: Academic Press, Inc., 1963.) 90s.

THE rapidly increasing number of chemical journals and other serial publications leads one to look more critically at each new series of "Advances in...", "Progress in . .. ", "Annual Reviews of ..." ", etc., in order to assess whether its existence is justified in terms of its value to chemists as well as of the profits it brings to its publishers. The test is passed by Advances in Physical Organic Chemistry, the first volume of a new series, which Sir Christopher Ingold, the leading contributor to the development of physical organic chemistry, describes in a short foreword as "an indispensably needed guide" to new 